\title{
Cisplatin-resistant prostate cancer model: Differences in antioxidant system, apoptosis and cell cycle
}

\author{
JAROMIR GUMULEC ${ }^{1,4}$, JAN BALVAN $^{1}$, MARKETA SZTALMACHOVA $^{1,2}$, MARTINA RAUDENSKA $^{1,4}$, \\ VERONIKA DVORAKOVA $^{1}$, LUCIA KNOPFOVA ${ }^{3}$, HANA POLANSKA ${ }^{1}$, KRISTYNA HUDCOVA ${ }^{1}$, \\ BRANISLAV RUTTKAY-NEDECKY ${ }^{2,4}$, PETR BABULA ${ }^{5}$, VOJTECH ADAM ${ }^{2,4}$, \\ RENE KIZEK $^{2,4}$, MARIE STIBOROVA ${ }^{6}$ and MICHAL MASARIK ${ }^{1,4}$
}

\begin{abstract}
${ }^{1}$ Department of Pathological Physiology, Faculty of Medicine, Masaryk University, CZ-625 00 Brno; ${ }^{2}$ Department of Chemistry and Biochemistry, Mendel University in Brno, CZ-613 00 Brno; ${ }^{3}$ Department of Experimental Biology, Faculty of Science,

Masaryk University, CZ-625 00 Brno; ${ }^{4}$ Central European Institute of Technology, Brno University of Technology, CZ-616 00 Brno; ${ }^{5}$ Department of Natural Drugs, Faculty of Pharmacy, University of Veterinary and Pharmaceutical Sciences, CZ-612 42 Brno; ${ }^{6}$ Department of Biochemistry, Faculty of Science, Charles University, CZ-128 40 Prague 2, Czech Republic
\end{abstract}

Received September 24, 2013; Accepted November 11, 2013

DOI: 10.3892/ijo.2013.2223

\begin{abstract}
Differences in the antioxidant system, apoptotic mechanism and in cell cycle between prostatic cell lines could partially elucidate the development of cisplatin resistance. The aim of this study was to identify the most characteristic parameter for a particular cell line and/or a particular cisplatin treatment using a general regression model and to assess whether it is possible to use measured parameters as markers of cisplatin resistance. This study integrates the results of viability, antioxidant, flow cytometric and quantitative PCR assays in order to characterize the resistance of prostate cancer to cisplatin. Cell growth using metabolic- (MTT) and impedance-based assays, the expression of key cell death signaling proteins (p53, Bax and Bcl-2), cell cycle, activity of antioxidant system-related proteins (superoxide dismutase, glutathione peroxidase, glutathione reductase and metallothionein) and free radical scavenging capacity assays [free radicals (FR), ferric reducing antioxidant power (FRAP), ABTS] were analyzed in the cell lines 22Rv1, PC-3 and PNT1A with respect to rising concentrations $(0-150 \mu \mathrm{M})$ and different length of cisplatin treatment (12-72 h). The non-functional-p53 PC-3 cell line showed decreased BAX $(\mathrm{p}<0.05)$ and, in contrast to PNT1A and 22Rv1, no cisplatin-induced effects on cell cycle. All cell lines showed increasing levels of free radical scavenging activity by ABTS, FRAP and FR assays in a time- and dosedependent manner ( $r>0.76$ at $\mathrm{p}<0.001$ for ABTS, FRAP and FR at $p<0.001)$. PC-3 showed increased $(p<0.05)$ levels of free radical scavenging activity by ABTS and FR methods. These
\end{abstract}

Correspondence to: Dr Michal Masarik, Department of Pathological Physiology, Faculty of Medicine, Masaryk University, Kamenice 5, CZ-625 00 Brno, Czech Republic

E-mail: masarik@med.muni.cz

Key words: prostate cancer, cell cycle, resistance, cisplatin, oxidative stress findings, together with significantly elevated MT, decreased p53 and Bax indicate PC-3 to be cisplatin-resistant. The differences in the antioxidant system and apoptotic mechanisms in PC-3 cells may elucidate the development of cisplatin resistance and indicate that this cell line may be further studied as a model of cytostatic resistance.

\section{Introduction}

Cis-diamminedichloroplatinum or cisplatin is an inorganic compound that is widely used as a therapy of cancers. The biochemical mechanisms of cisplatin cytotoxicity involve the binding of the drug to DNA and non-DNA targets and the subsequent induction of cell death through apoptosis, necrosis, or both (1). It follows that altered expression of regulatory proteins involved in signal transduction pathways that control the apoptosis, necrosis or cell defense mechanisms (Fig. 1) can additionally make certain types of cancer rather insensitive to cytotoxic effects of cisplatin $(2,3)$, which is, among others, case of later stages of prostate cancer. Cellular mechanisms of resistance to cisplatin are multifactorial and result in severe limitations in clinical use (4-6). Therefore, cisplatin resistance model was formed from prostatic cell lines PNT1A, PC-3, and $22 \mathrm{Rv} 1$ in this study. The PC-3 cell line was derived from a metastasis of a high grade androgen irresponsive prostate cancer. Cisplatin resistance is presumed in these cells due nonfunctional p53 (7). Tumor suppressor protein p53 plays a critical role in regulating cell cycle arrest, DNA repair and apoptosis (8). Accordingly, tumor cells lacking functional p53 were found more resistant to cisplatin than cells that contained functional p53 and the resistant cell lines were sensitized to cisplatin upon reconstitution with wild-type p53 (9).

Among other alterations in cellular response to the cisplatin, oxidative stress might be triggered $(10,11)$. In previous studies, the central role of mitochondria damage in the cisplatin-induced toxicity was demonstrated and it is suggested that it probably 


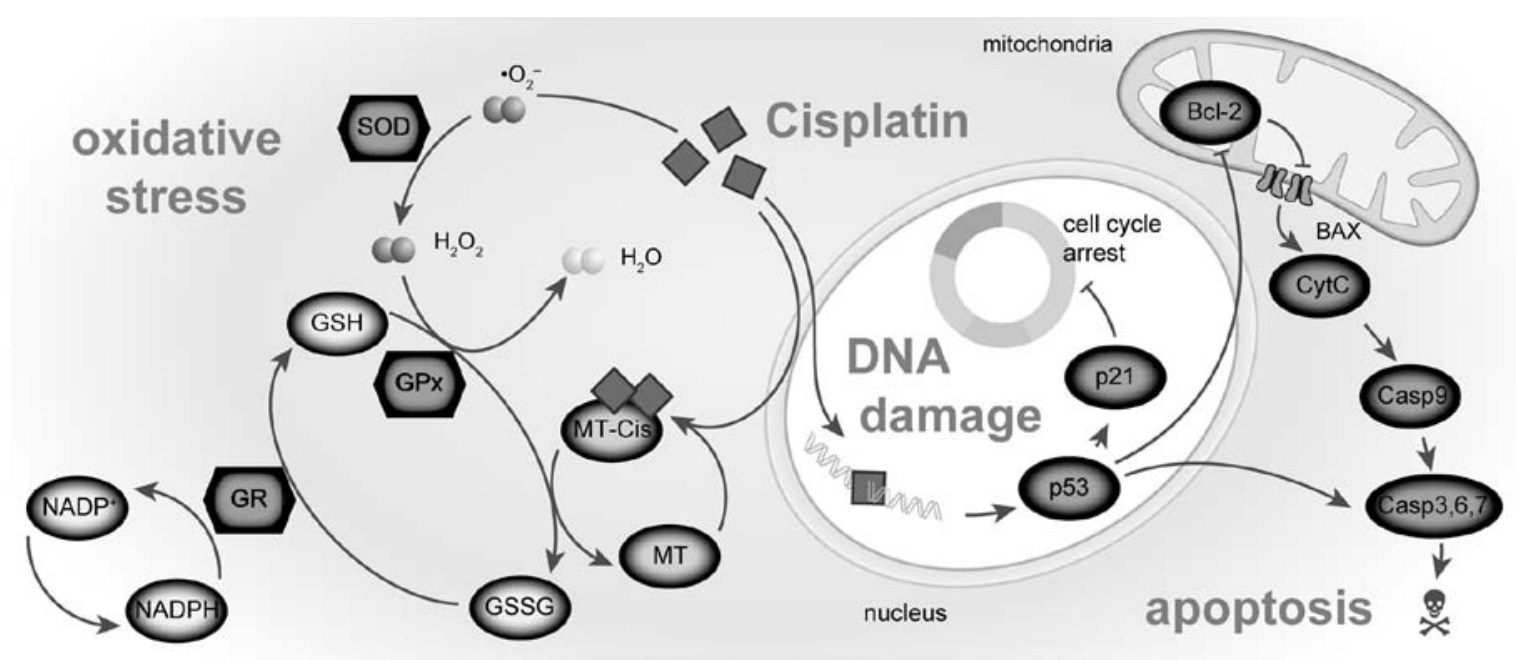

Figure 1. Cisplatin-induced DNA damage, oxidative stress and apoptosis. Cisplatin-cell interaction results in DNA damage, leading to p53 activation. DNA-repair mechanism is allowed due to $\mathrm{p} 21$-modulated cell cycle arrest. When damage is irreparable, p53 promotes apoptosis by inhibition of antiapoptic Bcl-2 and consequent caspase activation. Cisplatin binds to metallothionein (MT) and glutathione and thus oxidizes these compounds (GSH, reduced form of glutathione; GSSG, oxidized form of glutathione). Cisplatin generates superoxide radical $\left(\cdot \mathrm{O}_{2}^{-}\right)$, transformed by superoxiddismutase (SOD) to hydrogen peroxide, subsequently reduced by GSH in cooperation with glutathione peroxidase (GPx). GSSG is reduced by glutathione reductase (GR) in cooperation with reduced (NADPH).

occurs due to augmented ROS (reactive oxygen species) generation, with consequent impairment of mitochondrial function and structure, depletion of the key components of the mitochondrial antioxidant defense system (GSH and NADPH) and cellular death by apoptosis $(12,13)$. Therefore, understanding the expression of anti- and pro-apoptotic proteins and their relationship to redox system in the cells upon cisplatin treatment will provide valuable insight into the development of cisplatin resistance (11). Therefore, the expression of key apoptosis signaling genes (Bax and Bcl-2) and cell defensive thiol-containing molecule metallothionein (MT) were investigated in this study in different cisplatin concentrations and length of treatment. Additionally, main antioxidant enzymes superoxide dismutase (SOD), glutathione peroxidase (GPx) and glutathione reductase (GR) and antioxidant capacity with respect to the cisplatin treatment were analyzed in this study. MT binds rapidly to platinum and thus sequester cisplatin and remove it from the cells. This binding has primarily been associated with the development of resistance (9). However, there is still a level of inconsistence between studies. In some cases, the levels of MT are higher in cisplatin-resistant cells, but in other cases, the MT levels are unaffected (2).

In summary, differences in antioxidant system, apoptotic mechanism and in cell cycle between prostatic cell lines could partially elucidate the development of cisplatin resistance. Thus, the aim of this study was: i) to identify the most characteristic parameter for particular cell line and/or particular cisplatin treatment using general regression model and ii) to assess, whether it is possible to use measured parameters as markers of cisplatin resistance.

\section{Materials and methods}

Chemical and biochemical reagents. RPMI-1640 medium, Ham's F12 medium, fetal bovine serum (FBS) (mycoplasmafree), penicillin/streptomycin and trypsin were purchased from PAA Laboratories GmbH (Pasching, Austria). Phosphatebuffered saline (PBS) was purchased from Invitrogen Corp. (Carlsbad, CA, USA). Ethylenediaminetetraacetic acid (EDTA), cisplatin $0.5 \mathrm{mg} / \mathrm{ml}$ solution (Medac, Germany), RIPA buffer and all other chemicals of ACS purity were purchased from SigmaAldrich Co. (St. Louis, MO, USA), unless noted otherwise.

Cell cultures. Three human prostatic cell lines were used in this study: i) PNT1A human cell line established by immortalization of normal adult prostatic epithelial cells by transfection with a plasmid containing SV40 genome with a defective replication origin. The primary culture was obtained from the prostate of a 35 -year-old male post mortem; ii) $22 \mathrm{Rv} 1$ is a human prostate carcinoma epithelial cell line derived from a xenograft that was serially propagated in mice after castration-induced regression and relapse of the parental, androgen-dependent CWR22 xenograft. iii) PC-3 human cell line established from a grade 4 androgen independent and unresponsive prostatic adenocarcinoma from 62-year-old Caucasian male and derived from metastatic site in bone. All cell lines used in this study were purchased from Health Protection Agency Culture Collections (Salisbury, UK).

Culture conditions. PNT1A and 22Rv1 cells were cultured in RPMI-1640 medium with 10\% FBS. PC-3 cells were cultured in Ham's F12 medium with 7\% FBS. All media were supplemented with penicillin $(100 \mathrm{U} / \mathrm{ml})$ and streptomycin $(0.1 \mathrm{mg} / \mathrm{ml})$, and the cells were maintained at $37^{\circ} \mathrm{C}$ in a humidified incubator (Sanyo, Japan) with 5\% $\mathrm{CO}_{2}$.

Cisplatin treatment. The cisplatin treatment was initiated after cells reached $\sim 50 \%$ confluence. The concentration range 0,10 , $25,50,100,150 \mu \mathrm{mol} / 1$ was used for all cell lines. Time points for cell harvest and thus for all subsequent analyses were set subsequently: 12, 24, 48 and $72 \mathrm{~h}$. Thus, 6 (concentrations) $\mathrm{x}$ 4 (time points) lyzates were created. Cells were then harvested and washed four times with 1X PBS, pH 7.4.

Cell content quantification. Total cell content was analyzed using Casy model TT system (Roche Applied Science, USA) using following protocol: first, calibration was performed from 
samples of viable and necrotic cells. For necrotic cells, $100 \mu \mathrm{l}$ cell suspension and $800 \mu \mathrm{l}$ Casy Blue solution was mixed and left for $5 \mathrm{~min}$ in room temperature. Subsequently, $9 \mathrm{ml}$ Casy Tone was added. To prepare viable cell standard, $100 \mu \mathrm{l}$ cell suspension was mixed with $10 \mathrm{ml}$ Casy Tone. All subsequent measurements were performed on 100x diluted $100 \mu \mathrm{l}$ cell suspension. Prior each measurement, background was subtracted. All samples were measured in duplicates.

Measurements of cell viability - MTT test. The suspension of 5,000 cells was added to each well of standard microtiter plates. Volume of $200 \mu \mathrm{l}$ was transferred to 2-11 wells. Medium (200 $\mu \mathrm{l}$ ) was added to the first and to the last column (1 and 12, control). Plates were incubated for 2 days at $37^{\circ} \mathrm{C}$ to ensure cell growth. Medium was removed from columns 2 to 11 . Columns 3-10 were filled with $200 \mu \mathrm{l}$ of medium containing increasing concentration of cisplatin $(0-150 \mu \mathrm{mol} / \mathrm{l})$. As control, columns 2 and 11 were filled with medium without cisplatin. Plates were incubated for 12, 24, 48 and $72 \mathrm{~h}$; then, media were removed and replaced by a fresh medium, three times a day. Columns 1-11 were filled with $200 \mu \mathrm{l}$ of medium containing $50 \mu \mathrm{l}$ of MTT (5 $\mathrm{mg} / \mathrm{ml}$ in PBS) and incubated in a humidified atmosphere for $4 \mathrm{~h}$ at $37^{\circ} \mathrm{C}$, wrapped in aluminium foil. After the incubation, MTT-containing medium was replaced by $200 \mu 1$ of $99.9 \%$ dimethyl sulphoxide (DMSO) to dissolve MTT-formazan crystals. Then, $25 \mu \mathrm{l}$ of glycine buffer was added to all wells and absorbance was immediately determined at $570 \mathrm{~nm}$ (VersaMax microplate reader, Molecular Devices, Sunnyvale, CA, USA).

Cell growth and proliferation assay using impedance measurement with xCELLigence system. The xCELLigence system (Roche Applied Science and ACEA Biosciences, San Diego, CA, USA) consists of four main components: the RTCA analyzer, the RTCA station, the RTCA computer with integrated software and disposable E-plate 16. Firstly, the optimal seeding concentration for proliferation and cytotoxic assay was determined. After seeding the total number of cells in $200 \mu \mathrm{l}$ medium to each well in E-plate 16, the attachment, proliferation and spreading of the cells was monitored every $15 \mathrm{~min}$. All experiments were carried out for $250 \mathrm{~h}$. The results are expressed as relative impedance using the manufacturer's software (Roche Applied Science and ACEA Biosciences).

Flow cytometric analysis of cell cycle. The cells were harvested and fixed with ice-cold $70 \%$ ethanol for $30 \mathrm{~min}$. After washing with $1 \mathrm{X}$ PBS, the cells were incubated with DNA staining solution consisting of propidium iodide (PI; $50 \mu \mathrm{g} / \mathrm{ml}$ ) and RNase $(100 \mu \mathrm{g} / \mathrm{ml})$ for $30 \mathrm{~min}$ at $37^{\circ} \mathrm{C}$ in the dark. Samples were analyzed with FACSVerse flow cytometer (BD Biosciences, USA) and the data obtained were analyzed using FACSuite software (BD Biosciences).

RNA isolation and reverse transcription. High pure total-RNA isolation kit (Roche, Basel, Switzerland) was used for isolation. The medium was removed and samples were twice washed with $5 \mathrm{ml}$ of ice-cold PBS. Cells were scraped off, transferred to clean tubes and centrifuged at $20,800 \mathrm{xg}$ for $5 \mathrm{~min}$ at $4^{\circ} \mathrm{C}$. After this step, lysis buffer was added and RNA isolation was carried out according to manufacturer's instructions. Isolated RNA was used for cDNA synthesis. RNA (600 ng) was transcribed using transcriptor first strand cDNA synthesis kit (Roche, Switzerland) was used according to manufacturer's instructions. Prepared cDNA $(20 \mu \mathrm{l})$ from total-RNA was diluted with RNase-free water to $100 \mu \mathrm{l}$ and $5 \mu \mathrm{l}$ was directly analyzed by $7500 \mathrm{RT}-\mathrm{PCR}$ system (Applied Biosystems).

Quantitative polymerase chain reaction $(q-P C R)$. q-PCR was performed in triplicate using the TaqMan gene expression assay system with the 7500 RT-PCR system (Applied Biosystems) and the amplified DNA was analyzed by the comparative $\mathrm{Ct}$ method using $\beta$-actin as an endogenous control for metallothionein MT2A, Bax, Bcl-2 and p53 gene expression quantification. The primer and probe sets for $\beta$-actin (assay ID: Hs99999903 m1), MT2A (Hs02379661_g1) Bcl-2 (Hs99999018_m1), p53 (Hs01034649_m1), and Bax (Hs00180269_m1) were selected from TaqMan gene expression assays (Life Technologies, USA). q-PCR was performed under the following amplification conditions: total volume of $20 \mu \mathrm{l}$, initial incubation $50^{\circ} \mathrm{C} / 2 \mathrm{~min}$ followed by denaturation $95^{\circ} \mathrm{C} / 10 \mathrm{~min}$, then 45 cycles $95^{\circ} \mathrm{C} /$ $15 \mathrm{sec}, 60^{\circ} \mathrm{C} / 1 \mathrm{~min}$

Electrochemical detection of metallothionein. Electrochemical detection was used forquantification of metallothionein. Detection was carried out using AUTOLAB Analyser (EcoChemie, The Netherlands) with classical three-electrode arrangement using of differential pulse voltammetry Brdicka reaction. Analysed sample was accumulated on the surface of a working electrode which is represented by hanging mercury drop electrode. After accumulation, detection proceeded in a supporting electrolyte containing cobaltic $\left(\right.$ cobalt $^{3+}$ ) salt in ammonia buffer of $\mathrm{pH} 9.6$ (14).

Spectrophotometric measurement. Spectrophotometric measurements were carried out using an automated chemical analyser BS-400 (Mindray, P.R. China). It is composed of cuvette space tempered to $37 \pm 1^{\circ} \mathrm{C}$, reagent space with a carousel for reagents (tempered to $4 \pm 1^{\circ} \mathrm{C}$ ), sample space with a carousel for preparation of samples, and an optical detector. Transfer of samples and reagents is provided by robotic arm equipped with a dosing needle (error of dosage up to $5 \%$ of volume). Cuvette contents are mixed by an automatic mixer including a stirrer immediately after addition of reagents or samples. Contamination is reduced due to its rinsing system, including rinsing of the dosing needle as well as the stirrer by MilliQ water. For detection itself, the following range of wavelengths can be used - 340, 380, 412, 450, $505,546,570,605,660,700,740$, and $800 \mathrm{~nm}$.

Determination of SOD. Kit 19160 SOD (Sigma Aldrich, USA) was used for assay of SOD, EC 1.15.1.1. First, $200 \mu 1$ volume of reagent R1 (WTS solution 20 times diluted with buffer) was pipetted into a plastic cuvette and agent was incubated at $37^{\circ} \mathrm{C}$ for $108 \mathrm{sec}$. Afterwards, $20 \mu \mathrm{l}$ volume of sample was pipetted and in $378 \mathrm{sec}$, the reaction was started by adding $20 \mu \mathrm{l}$ volume of reagent R2 (enzyme solution 167 times diluted with buffer). It was incubated for $72 \mathrm{sec}$ and then absorbance was measured at $\lambda=450 \mathrm{~nm}$. Kinetic reaction was measured for $108 \mathrm{sec}$ and absorbance was read every $9 \mathrm{sec}$.

Determination of glutathione reductase and peroxidase. A glutathione reductase and peroxidase cellular activity assay kits 
(Sigma Aldrich) were used for GR and GPx activity determination. Reagents R1 and R2 were prepared by dissolving in an assay buffer $(100 \mathrm{mmol} / \mathrm{l}$ potassium phosphate buffer, $\mathrm{pH} 7.5$, with $1 \mathrm{mmol} / \mathrm{l}$ EDTA). The reagent R1 of $260 \mu \mathrm{l}$ volume ( $1.15 \mathrm{mmol} / \mathrm{l}$ oxidized glutathione in the assay buffer) was poured with $10 \mu \mathrm{l}$ of sample and $30 \mu \mathrm{l}$ volume of reagent R2 ( $1 \mathrm{mmol} / 1 \mathrm{NADPH}$ in GR assay buffer) into a plastic cuvette. The decrease in absorbance was measured at $340 \mathrm{~nm}$ using kinetic program for $126 \mathrm{sec}$.

Determination of antioxidant activity by the FRAP method. The FRAP method (ferric reducing antioxidant power) is based on the reduction of complexes of 2,4,6-tripyridyl-s-triazine with ferric chloride hexahydrate $\left(\mathrm{FeCl}_{3} \cdot 6 \mathrm{H}_{2} \mathrm{O}\right)$; these substances are almost colorless, and eventually slightly brownish. After the reduction, blue ferrous complexes are formed. Procedure for the determination was used as in Sochor et al (15). After $150 \mu \mathrm{l}$ volume of reagent is injected into a plastic cuvette with subsequent addition of a 3- $\mu 1$ sample, absorbance is measured at $605 \mathrm{~nm}$ for $12 \mathrm{~min}$. Difference between absorbance at the last (the 12th) min and the 2nd min of the assay procedure was used for calculating of the antioxidant activity.

Determination of antioxidant activity by the free radicals method. This method is based on ability of chlorophyllin (the sodium-copper salt of chlorophyl) to accept and donate electrons with a stable change of maximum absorption. This effect is conditioned by an alkaline environment and the addition of catalyst.

Procedure for the determination was used as in Sochor et al (15). Reagent of $150 \mu \mathrm{l}$ volume is injected into a plastic cuvette with subsequent addition of a 6- $\mu 1$ sample. Absorbance is measured at $450 \mathrm{~nm}$ in the second min of assay and the last (the 12th) min. Difference of the two absorbances is considered as an outputting value.

Statistical analysis. First, data were tested for normality using $\chi^{2}$-test and log-normal fitted data were recalculated to $\log$ scale. General regression model method was used to reveal relationships between multiple continuous and categorical variables.

Prior to regression analysis, Pearson's correlation was performed to verify concordant trends among cell lines. Subsequently, partial correlations were used to analyze residuals of time/concentration after adjustment of all other variables. To reveal differences between cell lines, Tukey's post-hoc test within homogeneous groups was employed after adjustment of all other variables. Prior to these analyses, residuals were tested for outliers (no-normally distributed data with outliers was excluded from subsequent analyses). Hierarchical clustering on standardized data was used to determine similar trends within determined parameters. Unless noted otherwise, $p<0.05$ was considered statistically significant. Software Statistica 10 (StatSoft, Inc., USA) was used for analysis.

\section{Results}

Effect of treatment on cell viability - comparison of MTT and impedance-based data. To assess the cytotoxic effect of cisplatin on prostate cell lines, and to select concentrations for further analyses, MTT test was performed with concentrations 0 (no drug added), 10, 25, 50, 100, 150, 200 and $250 \mu \mathrm{mol} / 1$ on all cell lines (Fig. 2A). Using logistic regression, $\mathrm{IC}_{50}$ concentrations were determined at time points $12,24,48$ and $72 \mathrm{~h}$. As expected, cisplatin cytotoxicity increases in time-dependent manner (Table I). To understand these temporal changes, real-time cell growth monitoring was employed with the same cisplatin concentrations. Using this method, transient increase in impedance resulting in peaks on growth curves was determined in the first $24 \mathrm{~h}$ of treatment (Fig. 2B). This method also showed a similar time-dependent cytotoxicity increase as seen by MTT. However, $\mathrm{IC}_{50}$ values calculated by this method were on average 1.3-fold higher compared to MTT and no significant correlation was observed between MTT- and impedance-based $\mathrm{IC}_{50}$ values $(\mathrm{r}=0.13$ at $\mathrm{p}=0.70)$.

Flow cytometric analysis of the cell cycle. To reveal the impact of cisplatin on the cell cycle, flow cytometric analysis was performed after the confluence of cells was $\sim 50 \%$. This confluence was reached within 24 to $48 \mathrm{~h}$ of treatment. Cisplatin-induced effects on cell cycle is evident in PNT1A and 22Rv1 cell lines (Fig. 2C and D). In these cells, $100 \mu \mathrm{M}$ cisplatin dose increases the proportion of sub-G1 stage cells; up to $26.7 \%$ and $73.2 \%$ in PNT1A and 22Rv1, respectively. Flow cytometric analysis of $22 \mathrm{Rv} 1$ cells exposed $150 \mu \mathrm{mol} / 1$ cisplatin was below the detection limits due to the low cell counts in the sample. In contrast, PC-3 cell line does not show cell cycle arrest, maintaining $<1.3 \%$ of cells in sub-G1 in all concentrations without significant increase or decrease.

Effect of treatment on gene expression. Subsequently, doseand time-dependent response of apoptosis- and oxidative stress-related genes was analyzed. First, the level of metallothionein isoform 2A (RNA and protein), cellular tumor antigen p53 (RNA and protein), apoptosis regulators $\mathrm{Bcl}-2$ and $\mathrm{Bcl}-2$ associated X protein (Bax, RNA only) were analyzed (Fig. 3).

All detected RNAs and proteins were affected in treatment time-, dose- or cell line-dependent manner to some extent. For a more comprehensive understanding, residual analysis of treatment time and cisplatin dose after adjustment of other variables is desirable. Conditions for such residual analysis are met, because all lines showed consistently significant increasing/ decreasing trends for all substances, the difference was seen only in the extent of increase/decrease. Partial correlations of time-, cell line-, and dose-adjusted residuals were determined to elucidate the unique contribution of the treatment time and dose individually (Table II). To analyze redundant trends, hierarchical cluster analysis of oxidative markers and RNA and protein was performed. As seen in Fig. 3A and B, Bcl-2, Bax and p53 show similar time- and dose-dependent response are thus clustered together.

First, the unique contribution of cisplatin dose after adjustment of all other variables (treatment time and cell line) is presented here. Significant elevation (i.e., significant partial correlation $r>0$ ) was determined in Bax (partial $r=0.34$ at $\mathrm{p}<0.01$ ) and metallothionein (partial $\mathrm{r}=0.73$ at $\mathrm{p}<0.001$ and $\mathrm{r}=0.45$ at $\mathrm{p}<0.001$ for RNA and protein, respectively). Second, unique contribution of treatment duration was analyzed. p53 and $\mathrm{Bcl}-2$ showed time-dependent increasing trends, $r=0.34$ at $\mathrm{p}<0.01$ and $\mathrm{r}=0.63$ at $\mathrm{p}<0.001$, respectively. The remaining 
A

(a) PNT1A

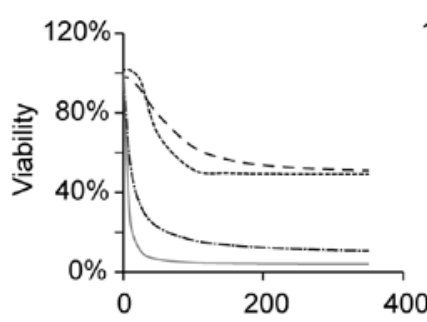

B

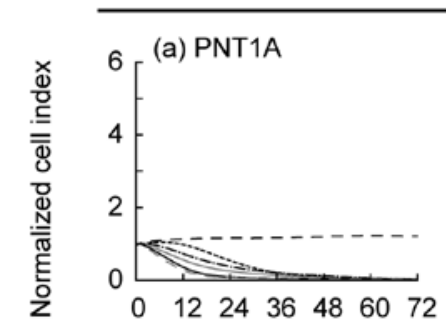

(b) 22Rv1

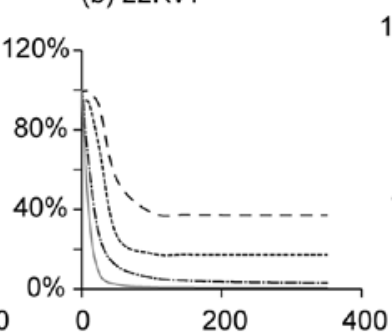

Applied cisplatin concentration $[\mu \mathrm{mol} / \mathrm{l}]$
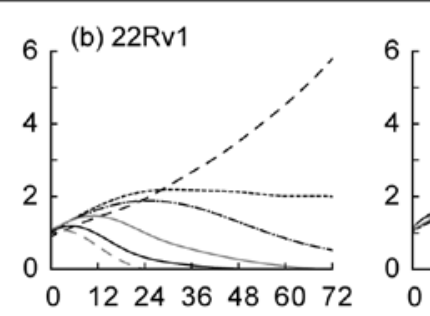

(c) PC-3

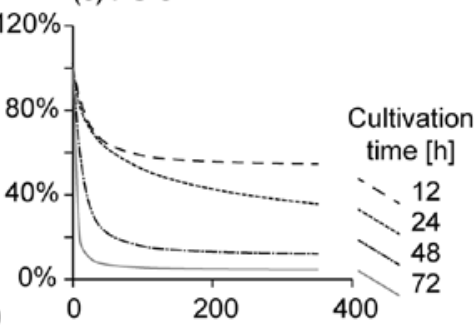

Applied cisplatin concentration [ $\mu \mathrm{mol} / \mathrm{l}]$

$\because 0$

$\checkmark 10$

25

25

100

Cultivation time [h]

C

(a) PNT1A

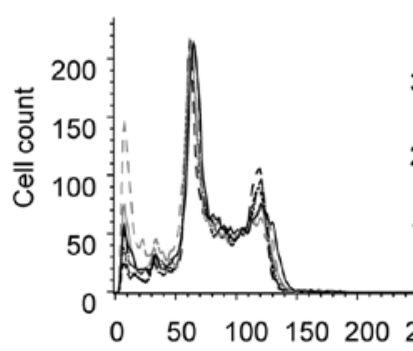

(c) 22Rv1

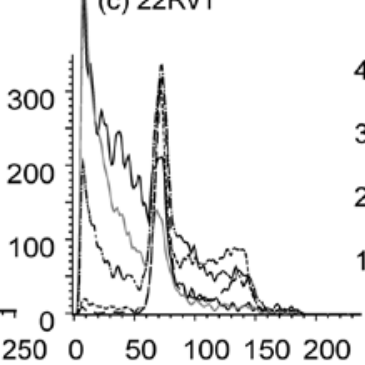

(c) PC-3

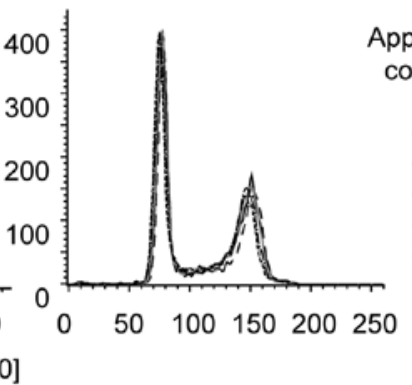

Applied cisplatin concentration [ $\mu \mathrm{mol} / 1]$

$\because 0$

- 10

25

50

$>100$ 150 (a) PNT1A

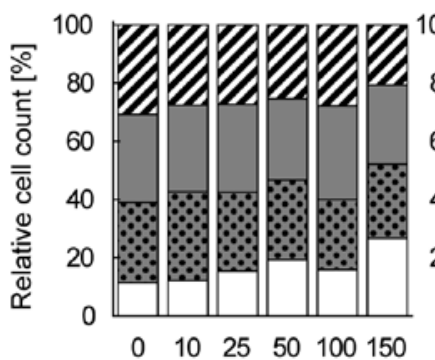

(b) 22Rv1

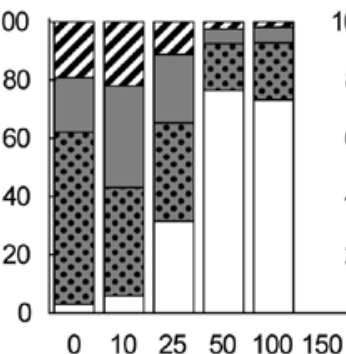

(c) $\mathrm{PC}-3$

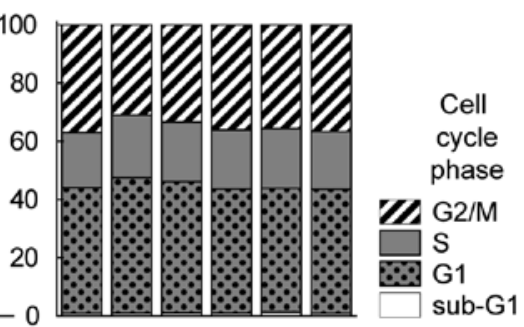

Applied cisplatin concentration $[\mu \mathrm{mol} / /]$

Figure 2. Cisplatin, cell growth and cell cycle. Each column shows one cell line (a-c). A, MTT test: dose-response curves measured in 12, 24, 48 and $72 \mathrm{~h}$. Evident metabolic activity decrease in later measurements. B, Real-time cell growth analysis. The impedance-based signal is represented as a cell index normalized to value 1.0 at the beginning of the treatment. Transient increase in cell index in the first $24 \mathrm{~h}$ as a result of cell size and/or adhesivity change following cisplatin treatment. C, Flow cytometric analysis of the cell cycle. Increasing proportion of sub-G1 (increasing peaks) evident in PNT1A and 22Rv1 cells and not in p53-defective PC-3 cells (a, b vs. c). D, Dose-dependent proportion of cells in various stages of the cell cycle. Note cisplatin treatments $>150 \mu \mathrm{M}$ are not shown for better clarity of charts.

Table I. Half-maximal concentrations. ${ }^{a}$

\begin{tabular}{|c|c|c|c|c|c|c|c|c|}
\hline \multirow[b]{2}{*}{ Cell line/time } & \multicolumn{4}{|c|}{$\operatorname{MTT~IC}_{50}(\mu \mathrm{mol} / \mathrm{l})$} & \multicolumn{4}{|c|}{ 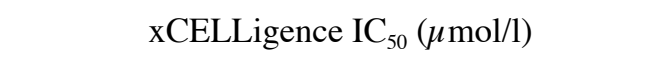 } \\
\hline & $12 \mathrm{~h}$ & $24 \mathrm{~h}$ & $48 \mathrm{~h}$ & $72 \mathrm{~h}$ & $12 \mathrm{~h}$ & $24 \mathrm{~h}$ & $48 \mathrm{~h}$ & $72 \mathrm{~h}$ \\
\hline PC-3 & 18.3 & 74.9 & 10.6 & 1.0 & 339.6 & 77.4 & 25.6 & 7.0 \\
\hline $22 \mathrm{Rv} 1$ & 40.4 & 30.8 & 12.7 & 7.9 & Undet. & 2413.8 & 10.5 & 2.6 \\
\hline PNT1A & 61.5 & 44.0 & 7.9 & 3.7 & 185.7 & 97.1 & 12.1 & 2.7 \\
\hline
\end{tabular}

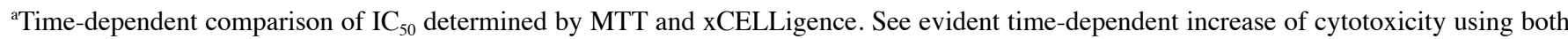
methods. Undet., undeterminable, out of range. 

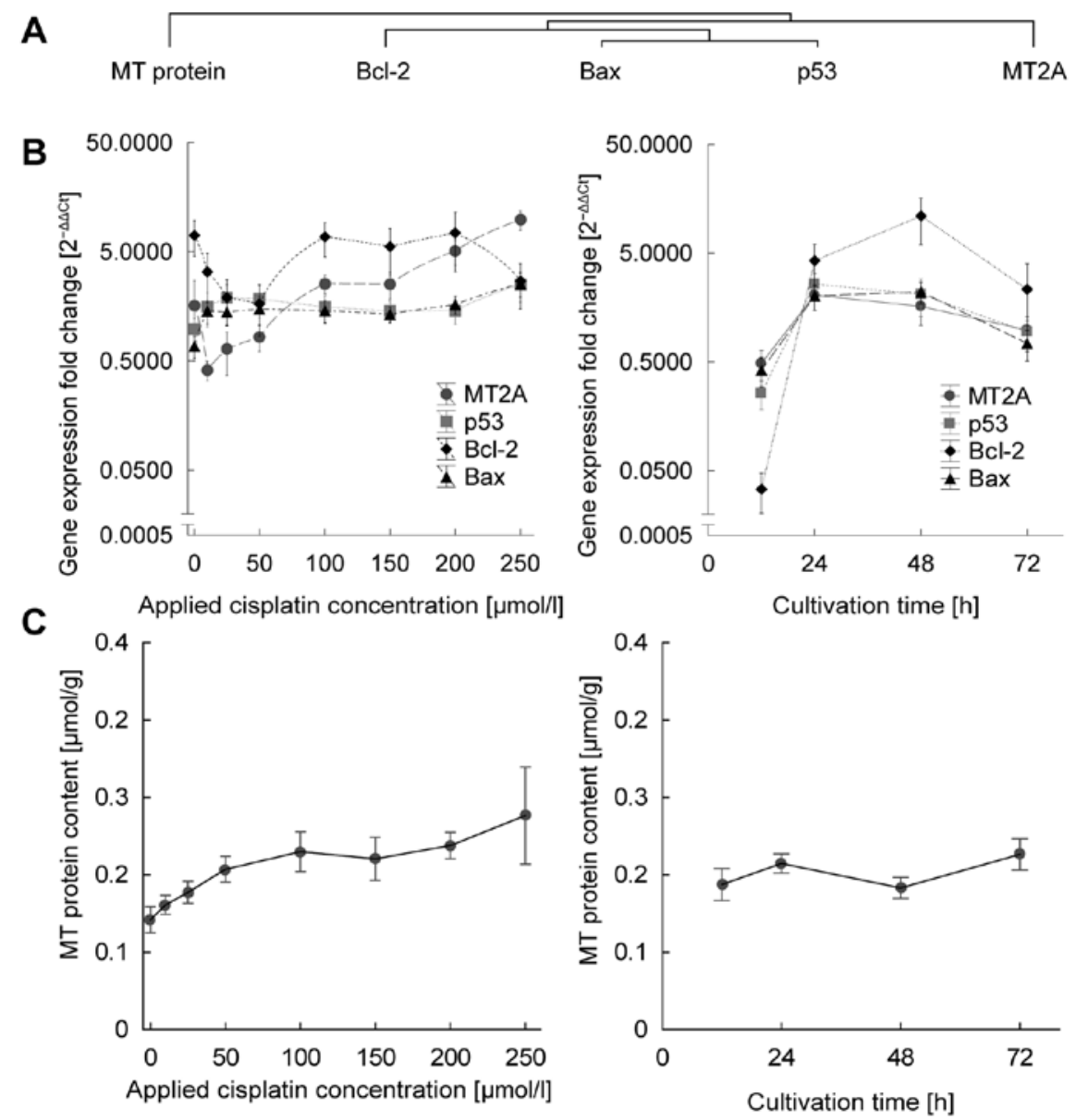

Figure 3. Gene expression and metallothionein protein level following cisplatin treatment. The effect of dosage after adjustment of all other variables shown in the left column, the effect of cultivation time on the right. A, Cluster analysis. See close relation of p53 and Bax in dendrogram resulting in similar trend of these genes in panel B. B, RNA level. There was distinct elevation of gene expression during first $24 \mathrm{~h}$. Note y-axis in log-scale, gene expression fold change relative to PNT1A cell line. MT2A, metallothionein 2A.C, Metallothionein protein level. Distinct cisplatin concentration-related MT increased. For subsequent correlation coefficients see Table II. Data displayed as mean \pm SE.

Table II. Dependence of parameters on time, cisplatin concentration and cell lines. ${ }^{\mathrm{a}}$

\begin{tabular}{|c|c|c|c|c|c|c|c|c|c|c|c|}
\hline $\begin{array}{l}\text { Correlation } \\
\text { coefficients (r) }\end{array}$ & $\begin{array}{l}\text { MT } \\
\text { protein }\end{array}$ & $\begin{array}{l}\text { MT } \\
\text { RNA }\end{array}$ & $\begin{array}{c}\text { p53 } \\
\text { RNA }\end{array}$ & $\begin{array}{l}\mathrm{Bcl}-2 \\
\text { RNA }\end{array}$ & $\begin{array}{l}\text { Bax } \\
\text { RNA }\end{array}$ & SOD & GR & GPx & FR & FRAP & ABTS \\
\hline \multicolumn{12}{|l|}{ Simple correlation } \\
\hline Time (h) & 0.03 & 0.09 & 0.12 & $0.36^{\mathrm{c}}$ & 0.05 & -0.14 & $-0.26^{\mathrm{b}}$ & $0.23^{\mathrm{b}}$ & $0.22^{\mathrm{b}}$ & 0.18 & 0.09 \\
\hline Cisplatin $(\mu \mathrm{mol} / \mathrm{l})$ & $0.43^{\mathrm{d}}$ & $0.71^{\mathrm{d}}$ & 0.03 & 0.02 & $0.24^{\mathrm{b}}$ & -0.18 & $-0.59^{\mathrm{d}}$ & $0.25^{\mathrm{b}}$ & $0.82^{\mathrm{d}}$ & $0.64^{\mathrm{d}}$ & $0.79^{\mathrm{d}}$ \\
\hline \multicolumn{12}{|l|}{ Multiple regression } \\
\hline Overall & $0.59^{\mathrm{d}}$ & $0.73^{\mathrm{d}}$ & $0.84^{\mathrm{d}}$ & $0.69^{\mathrm{d}}$ & $0.61^{\mathrm{d}}$ & $0.53^{\mathrm{d}}$ & $0.82^{\mathrm{d}}$ & $0.64^{\mathrm{d}}$ & $0.89^{\mathrm{d}}$ & $0.76^{\mathrm{d}}$ & $0.85^{\mathrm{d}}$ \\
\hline Time & 0.07 & 0.22 & $0.24^{\mathrm{b}}$ & $0.49^{\mathrm{d}}$ & 0.13 & -0.20 & $-0.43^{\mathrm{d}}$ & $0.36^{\mathrm{c}}$ & $0.52^{\mathrm{d}}$ & $0.36^{\mathrm{c}}$ & $0.26^{\mathrm{b}}$ \\
\hline Cisplatin $(\mu \mathrm{mol} / \mathrm{l})$ & $0.45^{\mathrm{d}}$ & $0.73^{\mathrm{d}}$ & 0.17 & 0.12 & $0.34^{c}$ & -0.21 & $-0.72^{\mathrm{d}}$ & $0.34^{\mathrm{c}}$ & $0.88^{\mathrm{d}}$ & $0.71^{\mathrm{d}}$ & $0.82^{\mathrm{d}}$ \\
\hline $22 \mathrm{Rv} 1$ cells & -0.14 & 0.10 & $0.34^{\mathrm{c}}$ & $0.63^{\mathrm{d}}$ & $0.46^{\mathrm{d}}$ & -0.22 & $0.59^{\mathrm{d}}$ & $0.48^{\mathrm{d}}$ & $-0.36^{\mathrm{c}}$ & $0.40^{\mathrm{d}}$ & $-0.39^{d}$ \\
\hline PC-3 cells & $0.43^{\mathrm{d}}$ & -0.13 & $-0.82^{\mathrm{d}}$ & $-0.46^{\mathrm{d}}$ & $-0.56^{\mathrm{d}}$ & $-0.29^{\mathrm{b}}$ & -0.03 & 0.06 & $0.36^{\mathrm{c}}$ & -0.01 & $0.40^{\mathrm{d}}$ \\
\hline
\end{tabular}

'Pearson correlation coefficients (R) showing ambiguous results. Second, general regression model is used to show multiple R (see 'Overall' row) and partial correlation coefficients (other parameters). Significant at ${ }^{\mathrm{b}} \mathrm{p}<0.05,{ }^{\mathrm{c}} \mathrm{p}<0.01,{ }^{\mathrm{d}} \mathrm{p}<0.001$. MT, metallothionein.

RNAs are not dose- or cultivation time-dependent. Despite this fact, time-dependent analysis of all genes exhibit biphasic relation (Fig. 3B). Cisplatin dramatically increases the expression, in particular in first $24 \mathrm{~h}$; up to 60-fold in Bcl-2, 10-fold in p53 and 5-fold in Bax and MT2A genes. However, after $24 \mathrm{~h}$ a plateau in expression is observed. As a result, the relation of MT RNA and 
A

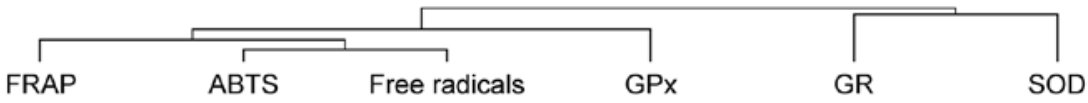

B
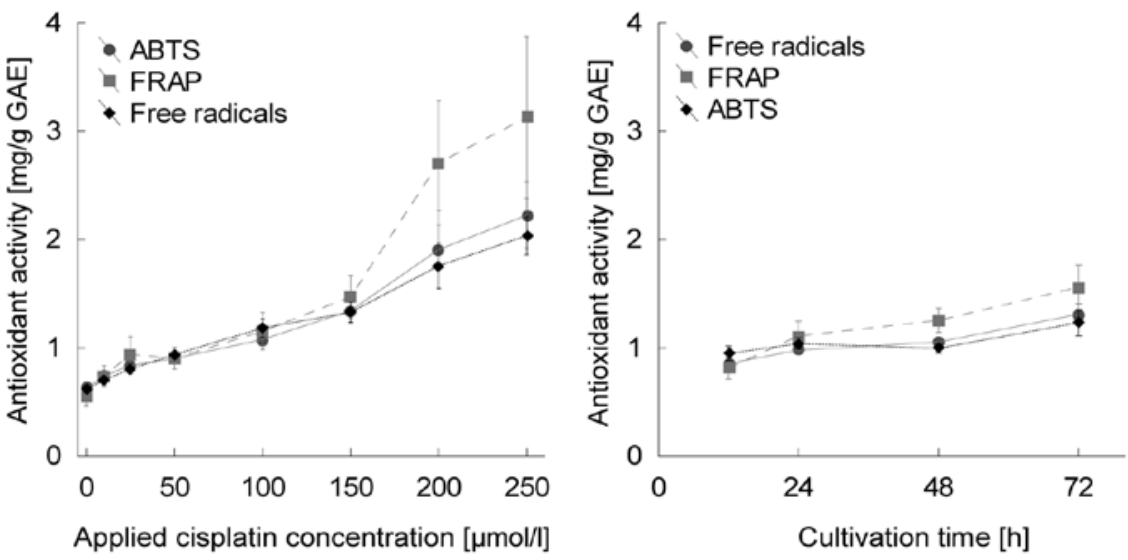

C

Applied cisplatin concentration $[\mu \mathrm{mol} / 1]$
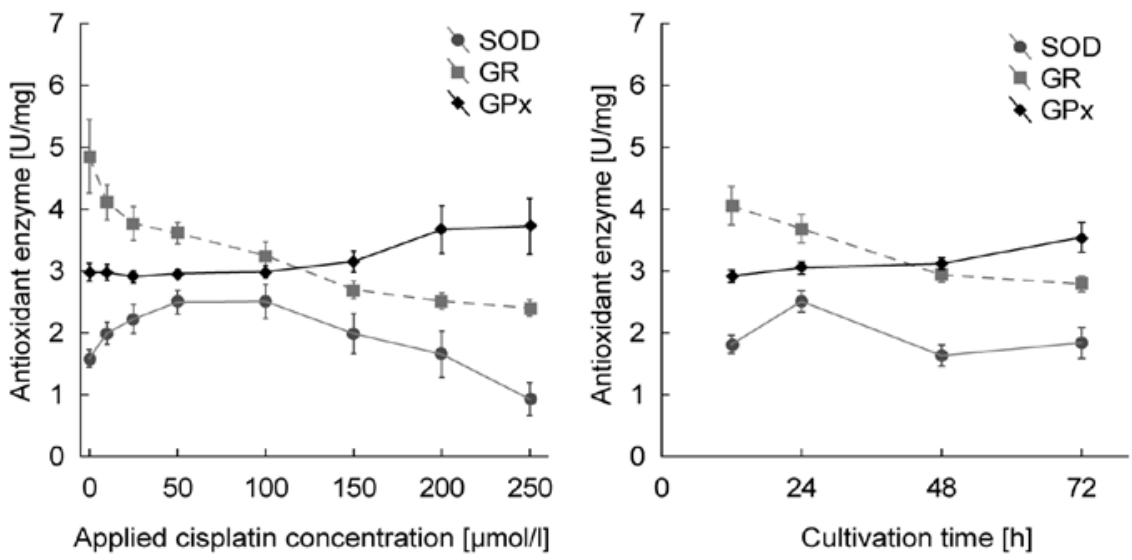

Figure 4. Oxidative stress after cisplatin treatment. The effect of dosage after adjustment of all other variables shown in the left column, the effect of cultivation time on the right. A, Cluster analysis. B, Markers of antioxidant capacity. Note the concordant trend of all three markers. C, Glutathione-related enzymes. Note the dose- and time-dependent GR decrease. Contrary to GR, no distinct cisplatin-related trends were determined in SOD. For subsequent correlation coefficients see Table II. Data displayed as mean \pm SE.

protein shows weak, but significant positive correlation $(r=0.24$ at $\mathrm{p}=0.016$ ).

Apart from gene expression analysis, protein level of MT was studied (Fig. 3C). Significant positive correlation was observed between MT protein and applied cisplatin dose $(\mathrm{r}=0.59$ at $\mathrm{p}<0.001)$ and no correlation was observed in relation to cultivation time.

Effect of treatment on antioxidant capacity. All markers of antioxidant capacity correlate with each other significantly (data not shown). This is well evident in Fig. 4B and corresponds to cluster analysis, where these markers are closely clustered (Fig. 4A). In terms of statistical significance, all markers of antioxidant capacity increased significantly in dose-dependent manner, $\mathrm{r}=0.88,0.71$ and 0.82 for free radicals, FRAP and ABTS, respectively, at $\mathrm{p}<0.001$. The duration of treatment affects parameters at lower levels of significance with $r=0.52$, 0.36 and 0.26 for free radicals, FRAP and ABTS (Fig. 4B).

With regard to glutathione-related enzymes, increasing dose- and time-dependent trend is shown only by glutathione peroxidase $(r=0.34$ and 0.36 for concentration and time at $\mathrm{p}<0.01$ ), in contrast, glutathione reductase decrease in both time- and dose-dependent manner (at $r=-0.72$ for concentration and $\mathrm{r}=-0.43$ for time at $\mathrm{p}<0.001)$. Superoxide dismutase showed no time- or concentration-dependent trends (Fig. 4C).

Effect of cell lines. Subsequently, the effect of cell lines was analyzed after adjustment of all other variables. Using Tukey's test for homogeneous groups, no significant difference, except in metallothionein RNA, between cell lines was identified. All other parameters showed significantly higher/lower trends between cell lines to some extent

To identify similar patterns between cell lines, cluster analysis was employed, creating two characteristic branches. The first branch comprises markers of antioxidant capacity, glutathione-related enzymes and metallothionein, in contrast, the second branch includes apoptosis-related genes and SOD (Fig. 5A).

Close similarity is observed between ABTS and FR, showing significant difference between tumorous cell lines only (higher in PC-3). MT, similarly to ABTS and FR, shows significant difference between tumorous lines only. Glutathione peroxidase shows significant difference between all cell lines, while lowest level was observed in healthy cell line, thus, showing similarity to glutathione reductase. Similar trend is observed also in FRAP, where only PNT1A and 22Rv1 differ significantly. 


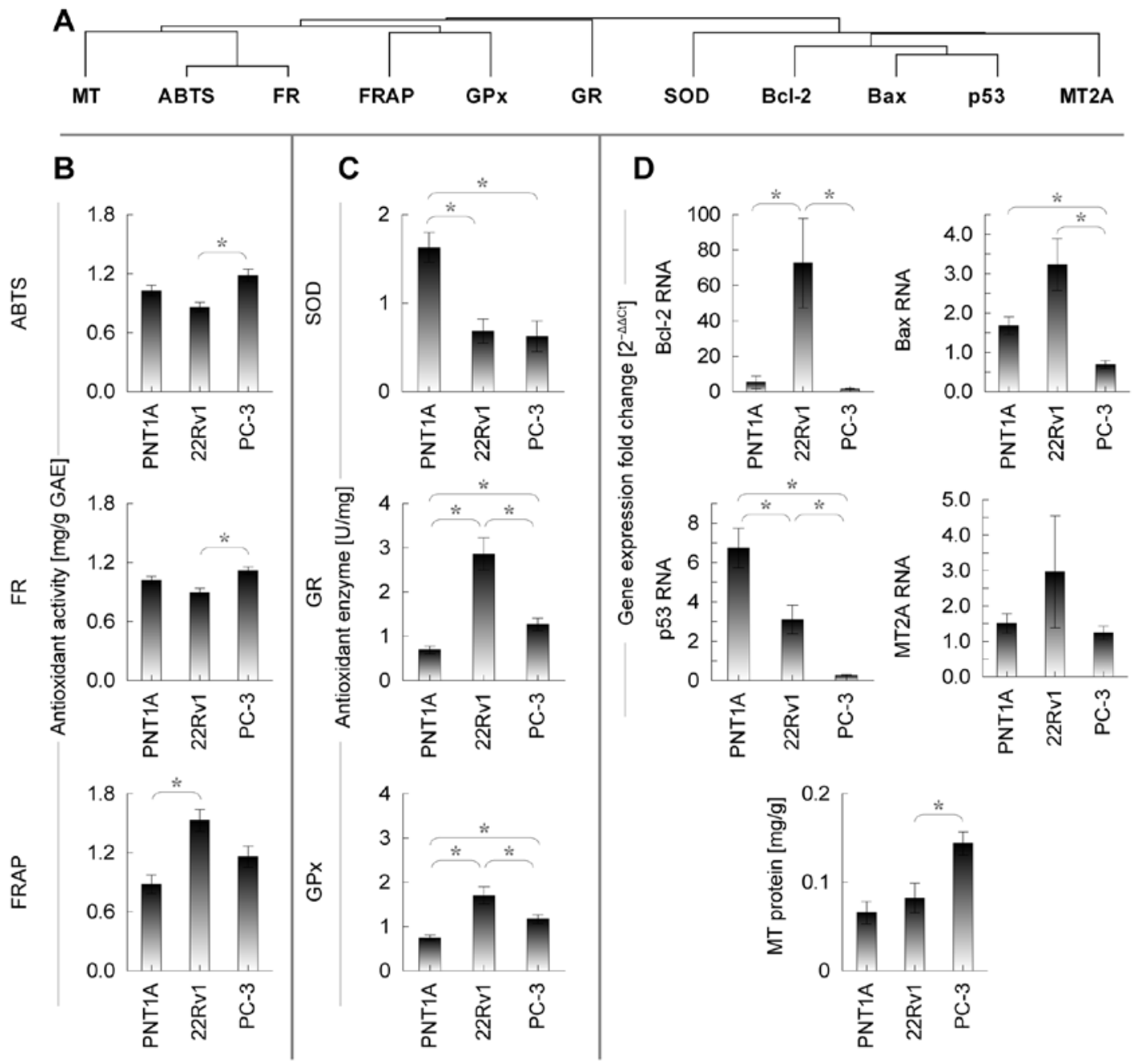

Figure 5. Cell lines and selected markers. The effect of each cell line after adjustment of treatment time and cisplatin dose. A, Cluster analysis. B, Markers of antioxidant capacity. Values displayed in $\mathrm{mg} / \mathrm{g}$ of galic acid equivalent. FRAP, ABTS - C, Glutathione-related enzymes. D, RNA and protein level of selected genes. RNA level in relative gene expression fold change relative to PNT1A. "Significant at $p<0.05$ using Tukey's post-hoc test. Data displayed as mean \pm SE.

With regard to apoptosis-related genes and superoxide dismutase, no difference can be seen in MT mRNA, significantly increased Bax in PC-3 cell line, significantly increased SOD in healthy PNT1A, significant difference between all cell lines in case of p53 (lowest in PC-3, highest in PNT1A) and significantly increased Bcl-2 in tumorous 22Rv1.

\section{Discussion}

This study provides time- and dose-dependent description of cisplatin-induced changes in antioxidant properties, apoptosis and cell cycle regulation on prostate cancer cell lines. These approaches clearly illustrate the development of resistance in advanced forms of prostate cancer, represented by the PC-3 cell line.

Cell growth, cell cycle. The results of viability assays distinctly show that the cytostatic effect of cisplatin is unpredictable in first hours of treatment, showing low cytotoxic potential, in particular, when detected using impedance-based method (Fig. 2A). This method provides transient increase in growth curves in particular in the first $24 \mathrm{~h}$ of treatment. Inasmuch as this detection method is influenced not only by the number of cells, but also by their size and adhesivity $(16,17)$ and while these transient changes cannot be caused by cell count increase in such a short interval, here we provide evidence of cisplatininfluenced change of cell morphology and/or adhesivity. The steady state stabilization occurs between 24-48 h.

Even after stabilization, high level of disagreement was observed between metabolic-based MTT and impedance-based viability assays. While MTT test demonstrates the most toxic effect on 'aggressive metastatic' PC-3 cells, impedance-based (cell amount-, size- and adhesivity-dependent) technique demonstrates, in contrast, least toxic effects on this cell line (compare MTT- and impedance-based $\mathrm{IC}_{50}$ values in Table I, Fig. 2). To find an answer for this seemingly conflicting finding it is appropriate to relate it to the changes in cell cycle and apoptosis in these cell lines.

PC-3 cells are hemizygous for chromosome 17p, and their single copy of the $p 53$ gene has a deletion at codon 138 that has caused a frameshift and a new in-frame stop codon at position 169 (18). As a result, PC-3 cells do not express p53 protein (19). Our results are in agreement with these findings (20): level of p53 RNA was almost under the detection limits in PC-3 cell line (Fig. 4). P53 acts as a tumor suppressor through the induction of growth arrest and apoptosis (8). PNT1A cell line, which was 
used in this experiment as a non-tumor model, was transfected using simian virus 40 (SV40) vector. However, SV40 induces T-antigen expression, which, on the other hand, inhibits the activity of p53 (21). Therefore, cell lines transfected using this vector have limited predictive value in terms of $\mathrm{p} 53$-dependent effects. Nevertheless, T-antigen p53 inhibition can be disrupted using oxidants (22), including cisplatin. The objective of the p53 detection in this study was neither to describe subtle concentration-dependent trends in p53 levels nor to describe p53-dependent cascades in detail, but rather to demonstrate a detectable induciblity of p53 expression when exposed to oxidative stress. The fact that detectable p53 content was determined in PNT1A under cisplatin load indicates p53-dependent pathways can be triggered in this cell line. Therefore, PNT1A might be used as model to study p53-dependent pathways, however, only if exposed to oxidative stress. The differences between p53-positive and negative cells are evident in our flow cytometric results: whereas both p53-expressing cells PNT1A and 22Rv1 show cisplatin-induced cell cycle changes accompanied by an increased proportion of sub-G1 phase cells, PC-3 cell does not show similar phenomenon (Fig. 2C and D). Similar phenomenon was demonstrated and linked with cisplatin resistance in non-small cell lung cancer cell line, for instance (23). It has been repeatedly demonstrated that apoptosis is the major mechanism for eliminating damaged cells in cisplatininduced cells injury (24-26). Thus, PC-3 cells without functional p53 signaling cascade may divide and grow when treated with cisplatin or other p53-targeting cytostatic drug. Because PC-3 is derived from an aggressive metastatic form of prostate cancer, using the description of the monitored genes and parameters, this study provides a good model of cisplatin resistance. In addition, similarly to cisplatin, more pronounced apoptosis in 22Rv1 compared to PC-3 was observed by Gravina et al when exposed to 5-azacitine or bicalutamide (27). Taken together, contradictory results of MTT assay and an impedance-based method can be caused by false reduced viability of PC-3, which could be caused by low metabolic activity of cells in autophagy status. The main principle of MTT assay is the tetrazolium salt reduction to formazan, which is quantified photometrically, by mitochondrial succinate dehydrogenase (SDH). SDH is only active in cells with an intact metabolism and respiratory chain. Fasting and oxidative stress, which is present by cisplatin treatment, was associated with a significant decrease of SDH activity, and the reduction was proportional with the decrease in the amount of SDH total protein $(28,29)$. Blocking apoptosis was found to promote autophagy in PC-3 and DU145 cells (30).

In accordance with this finding, we propose an impedancebased method as more reliable for growth monitoring of cytostatic-induced cells. Similar changes between these assays were reported also in our previous study (31).

Cisplatin effects - model of cisplatin resistance? To obtain initial insight into how all the markers and substances mentioned herein change after the exposure to cisplatin, 3-axis dependency graphs were visualized and calculated the simple correlations for each cell line. However, such analysis provides weak correlations and has limited power to emphasize complex multi-dimensional relations (Table II). Based on these graphs it is possible to draw the following conclusions: first, cisplatin concentration or treatment time clearly results in either increase or decrease in the levels of detected substances in all cell lines. Thus, none of the parameters increase in one cell line and decrease in the other in time- or dose-dependent manner. Second, both time and concentration cause more or less distinct changes in the levels of almost all monitored markers and substances. Third, some markers or substances rather increase, while others decrease, depending on the time or concentration.

Inasmuch as representation of graphs with their correlation coefficients would be confusing, statistically insufficiently powerful and, most importantly, such analysis would not refer to the obvious connection between the parameters, general regression model was used to show the effect of cell lines, concentrations of cisplatin and time of measurement simultaneously. This method provides benefits of both multiple linear regression and ANOVA and thus provide a more comprehensive view of all detected substances together. In this context, we focused on the identification of the most characteristic parameter for particular cell line and/or particular cisplatin treatment. Additionally, a hypothesis was verified, whether all measured markers may be used to describe cisplatin resistance.

To evaluate the effect of cisplatin concentration, duration of this cytotoxic effect or combination of these, partial correlations were calculated after the adjustment of all other variables. Partial correlations obtained by general regression model were subsequently compared to initially performed Pearson correlation results. Because significant trends were found mainly after adjusting using general regression model and no parameter correlated only before adjusting (i.e., in Pearson correlations), it is evident, that just variables 'concentration', 'time' and 'cell line' contribute to elucidate the variability (i.e., affect the level of detected substances). This manner explained up to $80 \%$ of the variability in data attributing it to the change in detection time, cisplatin concentration or cell line $\left(\mathrm{R}^{2}=0.80\right.$ in 'free radicals' method, for instance).

In this context, a hypothesis was formulated, whether all the measured parameters are rather influenced by the duration of the stress conditions (treatment time), or by the stress intensity (drug concentration). Whereas the markers of antioxidant capacity FRAP, ABTS and FR and GPx increase in dose- and time-dependent manner, p53 and Bcl-2 are time-dependent and BAX and MT are dose-dependent only. Interestingly, GR shows a decreasing time- and concentrationdependence. These findings are in agreement with what is inherently predictable: the increased p53 level contributes to apoptosis through Bax-cytochrome $\mathrm{C}$ mitochondrial apoptotic pathway by inhibition of Bcl-2 $(8,32)$ (Fig. 1). As a result of such balance, Bax level follows analogous trends in dose-, time- and cell line-dependent manner (Figs. 3 and 5). An agreement with these findings was observed by Kharaziha et al (33). Agreement with our data was also provided by $\mathrm{Li}$ et al demonstrating a simultaneous increase in ROS, p53 and caspases in response to another platinum-based cytostatic drug dicycloplatin (34).

Metallothionein protein level increases with increasing cisplatin concentration due to its (cisplatin-induced) reactiveoxygen-species buffering properties. In contrast, metallothionein is not affected by the duration of cisplatin treatment due to the fact that the concentration of this drug (and thus cisplatin-generated oxidative stress) remain relatively stable after steady state stabilization (Fig. 3). The highest MT levels are determined in an 
aggressive, metastasis-derived PC-3 cells. Similar finding was observed by several research teams (35-37). These data suggest MT is an important protective mechanism in cisplatin-induced stress and thus an important mechanism in the development and progression of cytostatic resistance. Such finding was already reported (35). No observed metallothionein RNA-protein match may appear to be a surprising result. However, it cannot be assumed, that significant RNA-protein correlation must be present. A pool of metallothionein capable to buffer limited amounts of oxidative stress is present more or less in all cells and thus RNA-response may not be apparent $(38,39)$.

With regard to the activity of enzymes included in oxidative stress buffering (SOD, GR and GPx), a specific pattern is observed. Whereas non-tumor cell line shows higher activity of SOD and lower activity of GR and GPx, tumorous cells show an inverse trend. When exposed to cisplatin, GPx increases, GR decreases and SOD does not show any significant trend. The decreasing dose- and time-dependent trends in glutathione reductase may seem surprising at first glance. Generally, one would assume that the increase in oxidative stress will also increase oxidized glutathione and thus the activity of glutathione reductase. However, cisplatin causes a depletion of the key components of the mitochondrial antioxidant defense system, including NADPH (13). Because of NADPH oxidation, GR activity is expected to decrease. Similar finding with GR and GPx when treated with cisplatin is reported by Pratibha et al in a rat model (40). The authors propose a cisplatininduced alteration in enzymatic antioxidant status with an increase in lipid peroxidation indicating that these enzymes play an important role in combating oxidative stress induced by free radicals (40).

With regard to markers of antioxidant capacity, it is worth mentioning that all radical scavenging activity detection methods correlate, showing an increase after cisplatin treatment. More pronounced increase is observed in tumorous cell lines particularly in the PC-3. These data suggest an increased ability of tumorous cells to cope with such conditions. There is no evidence on using these methods to describe antioxidant capacity on prostate cancer cell lines. This finding, together with elevated MT, decreased p53 and Bax suggest that the PC-3 cell line has unique features to cope with stress conditions and thus to be resistant to natural regulatory mechanisms such as apoptosis and cell cycle arrest and to stress cytostatics. Thus, this cell line may further be utilized as a model of cytostatic resistance, and markers and substances detected herein illustrate resistance development as well.

In this study, the cell-growth, cell cycle, apoptosis and oxidative stress-related methods were analyzed to describe the development of cisplatin resistance in prostate cancer. In p53-defective PC-3 cells no cisplatin-induced cell cycle arrest and reduced apoptosis was observed. In addition, higher free radical scavenging activity and higher metallothionein was observed in these cells. In contrast to impedance-based realtime cell growth analysis, reduced MTT-based viability suggests reduced metabolic activity and thus cells are expected to turn to autophagy. Thus, we propose an impedance-based method as more reliable for growth monitoring of cytostatic-treated cells.

Taken together, results of this study clearly illustrate, that the prostate cancer cell line $\mathrm{PC}-3$ shows signs of resistance to cytostatics accompanied by an increase in antioxidant capacity, by increased metallothionein expression, by inhibition of cell cycle arrest, and by decreased expression of proapoptic genes. Therefore, PC-3 cell line may be used for further analyses as a model for cytostatic resistance as well as protocols used in this study. However, precise mechanisms affecting the orientation of cells toward autophagy or apoptosis are open topics for further research.

\section{Acknowledgements}

The authors gratefully acknowledge financial support from the following projects: the Grant Agency of the Czech Republic (CYTORES GA CR P301/10/0356), Center of Experimental Biomedicine (CZ.1.07/2.3.00/20.0183) and the CentralEuropean Institute of Technology (CEITEC CZ.1.05/1.1.00/02.0068).

\section{References}

1. Gonzalez VM, Fuertes MA, Alonso C and Perez JM: Is cisplatininduced cell death always produced by apoptosis? Mol Pharmacol 59: 657-663, 2001.

2. Kartalou M and Essigmann JM: Mechanisms of resistance to cisplatin. Mutat Res 478: 23-43, 2001.

3. Niedner H, Christen R, Lin X, Kondo A and Howell SB: Identification of genes that mediate sensitivity to cisplatin. Mol Pharmacol 60: 1153-1160, 2001.

4. Herraez E, Gonzalez-Sanchez E, Vaquero J, et al: Cisplatin-induced chemoresistance in colon cancer cells involves FXR-dependent and FXR-independent up-regulation of ABC proteins. Mol Pharm 9: 2565-2576, 2012.

5. Liu YB, Bernauer AM, Yingling CM and Belinsky SA: HIF1 alpha regulated expression of XPA contributes to cisplatin resistance in lung cancer. Carcinogenesis 33: 1187-1192, 2012.

6. Wu YC, Ling TY, Lu SH, et al: Chemotherapeutic sensitivity of testicular germ cell tumors under hypoxic conditions is negatively regulated by SENP1-controlled sumoylation of OCT4. Cancer Res 72: 4963-4973, 2012.

7. Skjoth IHE and Issinger OG: Profiling of signaling molecules in four different human prostate carcinoma cell lines before and after induction of apoptosis. Int J Oncol 28: 217-229, 2006.

8. Faria MHG, Neves EHC, Alves MKS, Burbano RMR, De Moraes MO and Rabenhorst SHB: TP53 mutations in astrocytic gliomas: an association with histological grade, TP53 codon 72 polymorphism and p53 expression. APMIS 120: 882-889, 2012.

9. Fuertes MA, Alonso C and Perez JM: Biochemical modulation of cisplatin mechanisms of action: enhancement of antitumor activity and circumvention of drug resistance. Chem Rev 103: 645-662, 2003.

10. Righetti SC, Perego P, Carenini N, et al: Molecular alterations of cells resistant to platinum drugs: role of PKC alpha. Biochim Biophys Acta 1763: 93-100, 2006.

11. Brozovic A, Ambriovic-Ristov A and Osmak M: The relationship between cisplatin-induced reactive oxygen species, glutathione, and BCL-2 and resistance to cisplatin. Crit Rev Toxicol 40: 347-359, 2010.

12. Santos NAG, Catao CS, Martins NM, Curti C, Bianchi MLP and Santos AC: Cisplatin-induced nephrotoxicity is associated with oxidative stress, redox state unbalance, impairment of energetic metabolism and apoptosis in rat kidney mitochondria. Arch Toxicol 81: 495-504, 2007.

13. Martins NM, Santos NAG, Curti C, Bianchi MLP and Santos AC: Cisplatin induces mitochondrial oxidative stress with resultant energetic metabolism impairment, membrane rigidification and apoptosis in rat liver. J Appl Toxicol 28: 337-344, 2008.

14. Kizek R, Trnkova L and Palecek E: Determination of metallothionein at the femtomole level by constant current stripping chronopotentiometry. Anal Chem 73: 4801-4807, 2001.

15. Sochor J, Ryvolova M, Krystofova O, et al: Fully automated spectrometric protocols for determination of antioxidant activity: advantages and disadvantages. Molecules 15: 8618-8640, 2010.

16. Quereda JJ, Martinez-Alarcon L, Mendoca L, et al: Validation of xCELLigence real-time cell analyzer to assess compatibility in xenotransplantation with pig-to-baboon model. Transplant Proc 42: 3239-3243, 2010. 
17. Vistejnova L, Dvorakova J, Hasova M, et al: The comparison of impedance-based method of cell proliferation monitoring with commonly used metabolic-based techniques. Neuroendocrinol Lett 30: 121-127, 2009.

18. Carroll AG, Voeller HJ, Sugars L and Gelmann EP: p53 oncogene mutations in 3 human prostate-cancer cell-lines. Prostate 23: 123-134, 1993.

19. Rubin SJ, Hallahan DE, Ashman CR, et al: 2 prostate carcinoma cell-lines demonstrate abnormalities in tumor suppressor genes. J Surg Oncol 46: 31-36, 1991.

20. Sztalmachova M, Hlavna M, Gumulec J, et al: Effect of zinc(II) ions on the expression of pro- and anti-apoptotic factors in highgrade prostate carcinoma cells. Oncol Rep 28: 806-814, 2012.

21. Schmieg FI and Simmons DT: Characterization of the in vitro interaction between SV40 T-antigen and p53: mapping the p53 binding-site. Virology 164: 132-140, 1988.

22. Gonin S, Diaz-Latoud C, Richard MJ, et al: p53/T-antigen complex disruption in T-antigen transformed NIH3T3 fibroblasts exposed to oxidative stress: correlation with the appearance of a Fas/ APO-1/CD95 dependent, caspase independent, necrotic pathway. Oncogene 18: 8011-8023, 1999.

23. Barr MP, Gray SG, Hoffmann AC, et al: Generation and characterisation of cisplatin-resistant non-small cell lung cancer cell lines displaying a stem-like signature. Plos One 8: 1-19, 2013.

24. Liu J, Liu YP, Habeebu SSM and Klaassen CD: Metallothionein (MT)-null mice are sensitive to cisplatin-induced hepatotoxicity. Toxicol Appl Pharmacol 149: 24-31, 1998.

25. Siddik ZH: Cisplatin: mode of cytotoxic action and molecular basis of resistance. Oncogene 22: 7265-7279, 2003.

26. Wang D and Lippard SJ: Cellular processing of platinum anticancer drugs. Nat Rev Drug Discov 4: 307-320, 2005.

27. Gravina GL, Marampon F, Di Staso M, et al: 5-Azacitidine restores and amplifies the bicalutamide response on preclinical models of androgen receptor expressing or deficient prostate tumors. Prostate 70: 1166-1178, 2010

28. Aitken RJ, Whiting S, De Iuliis GN, McClymont S, Mitchell LA and Baker MA: Electrophilic aldehydes generated by sperm metabolism activate mitochondrial reactive oxygen species generation and apoptosis by targeting succinate dehydrogenase. J Biol Chem 287: 33048-33060, 2012.
29. Komatsu M, Waguri S, Ueno T, et al: Impairment of starvationinduced and constitutive autophagy in Atg7-deficient mice. J Cell Biol 169: 425-434, 2005.

30. Cao C, Subhawong T, Albert JM, et al: Inhibition of mammalian target of rapamycin or apoptotic pathway induces autophagy and radiosensitizes PTEN null prostate cancer cells. Cancer Res 66: 10040-10047, 2006.

31. Masarik M, Gumulec J, Hlavna M, et al: Monitoring of the prostate tumour cells redox state and real-time proliferation by novel biophysical techniques and fluorescent staining. Integr Biol 4: 672-684, 2012.

32. Kuwana T and Newmeyer DD: Bcl-2-family proteins and the role of mitochondria in apoptosis. Curr Opin Cell Biol 15: 691-699, 2003.

33. Kharaziha $\mathrm{P}$, Rodriguez $\mathrm{P}, \mathrm{Li} \mathrm{Q}$, et al: Targeting of distinct signaling cascades and cancer-associated fibroblasts define the efficacy of Sorafenib against prostate cancer cells. Cell Death Dis 3: 1-10, 2012

34. Li GQ, Chen XG, Wu XP, et al: Effect of dicycloplatin, a novel platinum chemotherapeutical drug, on inhibiting cell growth and inducing cell apoptosis. Plos One 7: 1-13, 2012.

35. Kondo Y, Kuo SM, Watkins SC and Lazo JS: Metallothionein localization and cisplatin resistance in human hormone-independent prostatic tumor-cell lines. Cancer Res 55: 474-477, 1995.

36. Suzuki Y, Kondo Y, Himeno S, Nemoto K, Akimoto M and Imura N: Role of antioxidant systems in human androgen-independent prostate cancer cells. Prostate 43: 144-149, 2000.

37. Yamasaki M, Nomura T, Sato F and Mimata $\mathrm{H}$ : Metallothionein is up-regulated under hypoxia and promotes the survival of human prostate cancer cells. Oncol Rep 18: 1145-1153, 2007.

38. Costello LC, Fenselau CC and Franklin RB: Evidence for operation of the direct zinc ligand exchange mechanism for trafficking, transport, and reactivity of zinc in mammalian cells. J Inorg Biochem 105: 589-599, 2011.

39. Bell SG and Vallee BL: The metallothionein/thionein system: an oxidoreductive metabolic zinc link. Chembiochem 10: 55-62, 2009.

40. Pratibha R, Sameer R, Rataboli PV, Bhiwgade DA and Dhume CY: Enzymatic studies of cisplatin induced oxidative stress in hepatic tissue of rats. Eur J Pharmacol 532: 290-293, 2006. 